\title{
AVALIAÇÃO DE UMA NOVA MICROTÉCNICA DE FIXAÇÃO DE COMPLEMENTO (GARCIA \& SOTELO, 1991) PARA O DIAGNÓSTICO DA DOENÇA DE CHAGAS CRÔNICA COM DIFERENTES PREPARAÇÕES ANTIGÊNICAS
}

\begin{abstract}
Aldo Matos e Luis Eduardo Ramírez
No presente trabalho, avalia-se a nova fixação de complemento, comparativamente à imunofluorescência indireta, para o diagnóstico da doença de Chagas crônica, utilizando um extrato aquoso de formas epimastigotas do Trypanosoma cruzi e três extratos etanólicos: um de epimastigotas, um de tripomastigotas e outro de amastigotas obtidas de cultura. Empregaram-se 236 amostras testadas por imunofluorescência indireta: 109 positivas (20 com diagnóstico parasitológico) e 127 amostras negativas (96 de doadores de sangue e 31 de portadores de outras patologias). Os resultados mostraram que é possível obter reação positiva em amostras diluídas até 1:16. Os melhores limiares de reatividade encontrados foram a diluição 1:4 para o extrato etanólico de amastigotas e 1:2 para os demais antígenos. Os índices de correlação entre a nova fixação de complemento e imunofluorescência indireta indicaram o extrato etanólico de epimastigotas como o antígeno mais adequado para fins de diagnóstico entre as preparações testadas, tendo apresentado indice de co-positividade com a imunofluorescência indireta de 0,92207 e indice de co-negatividade de 0,90000. Conclui-se que a nova fixação de complemento mostrou-se ser uma microtécnica semiquantitativa rápida, sensível, barata e de fácil execução, aplicável ao diagnóstico da doença de Chagas crônica.
\end{abstract}

Palavras-chaves: Doença de Chagas. Diagnóstico. Fixação de complemento.

Não obstante as recentes conquistas no combate a sua transmissão, a doença de Chagas ainda permanece entre as principais endemias da América Latina. Dias5 avaliou que, aproximadamente, 100 milhões de latinoamericanos vivem sob o risco de contrair a tripanosomíase americana e que algo em torno de 16 a 18 milhões já se encontram infectados.

Além da transmissão vetorial, existem, comprovadamente, a transmissão transfusional ou por transplante de órgãos de doadores chagásicos para receptores sadios, levando a quadros clínicos variados, destacando-se, por sua gravidade, a cardiomegalia e a dilatação dos órgãos cavitários, pricipalmente cólon e esôfago. Assim o diagnóstico da doença aplica-se tanto para orientação do tratamento específico como para a seleção de doadores de sangue ou órgãos.

Disciplina de Parasitologia da Faculdade de Medicina do Triângulo Mineiro, Uberaba, MG.

Endereço para correspondência: Prof. Aldo Matos. Disciplina de Parasitologia/DCB/FMTM, Praça Thomaz Ulhôa 706, 38025-250 Uberaba, MG.

Recebido para publicação em 05/02/97.
Uma vez que o diagnóstico clínico da doença de Chagas é dificultado pela elevada freqüência de pacientes assintomáticos e que os métodos de diagnóstico parasitológico têm sua sensibilidade diminuída concomitantemente à queda da parasitemia, assumem grande importância, sobretudo na fase crônica, os métodos imunológicos de diagnóstico. Contudo, ainda hoje, não foi encontrado um teste sorológico definitivo para o diagnóstico da doença de Chagas, permanecendo a necessidade de avaliar a mesma amostra de soro através de duas ou mais metodologias diferentes, demandando tempo e elevando os custos do diagnóstico laboratorial.

Garcia e Sotelo 6 procurando resgatar a reação de fixação de complemento como prova para diagnóstico sorológico, apresentaram uma nova metodologia que denominaram nova fixação de complemento (NFC), a qual apresentou bons resultados inicialmente para o diagnóstico de neurocistecercose e mais tarde, para diagnosticar a doença de Chagas, mostrando-se sensível e com boa especificidade quando realizada em soro não diluído7. Em contraste com a reação de fixação de complemento clássica, que utiliza antígenos 
Matos A, Ramírez LE. Avaliação de uma nova microtécnica de fixação de complemento (Garcia E Sotelo, 1991) para o diagnóstico da doença de Chagas crônica com diferentes preparaçôes antigênicas. Revista da Sociedade Brasileira de Medicina Tropical 30:493-499, nov-dez, 1997.

liofilizados instáveis após regenerados, a NFC utiliza como antígeno, um extrato alcoólico, o qual mantém constantes suas propriedades por um ano ou mais, mesmo armazenado à temperatura ambiente, permitindo que a reação seja feita rotineiramente sem necessitar retitulá-lo. A NFC utiliza um soro hiperimune de cobaias como fonte simultânea de complemento e hemolisina e como revelador, uma suspensão de eritrócitos humanos tipo $\mathrm{O}$. Já a fixação de complemento clássica apresenta os inconvenientes da necessidade de utilizar fontes distintas de complemento e hemolisina e um sistema revelador composto de eritrócitos de carneiros. Além disso, a NFC é uma reação rápida, executada em aproximadamente duas horas, ao passo que a reação de fixação de complemento clássica demora quase um dia.

$O$ presente trabalho avalia a NFC para O diagnóstico da doença de Chagas crônica, em amostras diluídas, quanto a sua sensibilidade e especificidade utilizando quatro diferentes preparações antigênicas de T. cruzi e compara os resultados com aqueles previamente obtidos por imunofluorescência indireta (IFI).

\section{MATERIAIS E MÉTODOS}

Amostras. Empregaram-se 236 amostras testadas por IFI: 109 positivas, entre elas 20 também com diagnóstico parasitológico, e 127 amostras negativas, 96 provenientes de doadores de sangue, 6 de portadores de lues, 5 de portadores de toxoplasmose, 10 de portadores de leishmaniose tegumentar americana, 8 de portadores de malária ( 4 de infectados por $P$. falciparum e 4 por $P$. vivax) e duas de portadores de doença reumática.

Obtenção dos Antígenos. As preparações antigênicas foram obtidas a partir da cepa Y do T. cruzi, mantida por repiques sucessivos em camundongos até o momento da inoculação em meio LIT3 para obtenção das formas epimastigotas ou em monocamada de células L929, mantidas com meio HAM F-12 suplementado com $10 \%$ de soro fetal bovino (SFB) para obtenção das formas amastigotas e tripomastigotas.

As formas epimastigotas foram isoladas da cultura ativa a cada oito dias por centrifugação a $1125 \mathrm{~g}$ por 15 minutos a $4^{\circ} \mathrm{C}$, lavadas nas mesmas condições com salina esterilizada e armazenadas em freezer a $-70^{\circ} \mathrm{C}$ até o momento de serem processadas.
As formas amastigotas foram isoladas, a cada seis dias, do tripsinizado da monocamada de células L929, centrifugado a $405 \mathrm{~g}$ por 5 minutos, lavadas nas mesmas condições três vezes com salina esterilizada e armazenadas em freezer a $-70^{\circ} \mathrm{C}$ até o momento de serem processadas.

As formas tripomastigotas foram isoladas do sobrenadante da cultura celular, a cada três dias, utilizando as mesmas condições de centrifugação e armazenamento descritas para as formas epimastigotas.

O extrato aquoso de epimastigotas (EAE) foi preparado segundo a metodologia para a obtenção do antígeno número 4 descrita por Almeida e Fife1.

Preparou-se o extrato etanólico de epimastigotas (EEE) segundo a metodologia descrita por Garcia e cols7.

Para a obtenção do extrato etanólico de tripomastigotas (EET), 50mg de tripomastigotas liofilizadas foram transferidos para um gral. Por três vezes, misturou-se com acetona e se deixou secar a $37^{\circ} \mathrm{C}$. O material obtido foi triturado até se obter um pó fino com textura de talco, ao qual foi adicionado etanol na proporção de $1,5 \mathrm{ml}$ para $50 \mathrm{mg}$ de pó. Esta suspensão alcoólica, mantida ao abrigo da luz, foi agitada, vigorosamente, três vezes ao dia por quinze dias. Terminado este prazo, a suspensão foi centrifugada a $720 \mathrm{~g}$ e temperatura ambiente por cinco minutos. O sobrenadante foi armazenado à temperatura ambiente e ao abrigo da luz.

Para a obtenção do extrato etanólico de amastigotas (EEA) uilizou-se a mesma metodologia descrita para o antígeno EET, alterando-se a massa de liofilizado para 100mg e o volume de etanol para $2 \mathrm{ml}$.

Obtenção do complemento-hemolisina. O complemento e a hemolisina foram obtidos conjuntamente no soro de cobaias segundo a metodologia descrita por Garcia e Sotelo6.

Titulação do complemento-hemolisina. O complemento e a hemolisina foram titulados, conjuntamente e em duas etapas, utilizando dois soros controles positivos e dois soros controles negativos, classificados por IFI e HAI e previamente inativados a $56^{\circ} \mathrm{C}$ por 30 minutos.

A primeira etapa foi realizada segundo Garcia e Sotelo6 resumidamente: tomaram-se 
Matos A, Ramírez LE. Avaliação de uma nova microtécnica de fixação de complemento (Garcia E Sotelo, 1991) para o diagnóstico da doença de Chagas crônica com diferentes preparações antigênicas. Revista da Sociedade Brasileira de Medicina Tropical 30:493-499, nov-dez, 1997.

oito frascos de complemento-hemolisina numerando-os de 1 a 8 e reconstituindo o liofilizado com PBS em volume variando em escala de $1 \mathrm{ml}$, começando com $3 \mathrm{ml}$ para o frasco número 1 até $10 \mathrm{ml}$ para o frasco número 8. Para ensaiar cada frasco de complementohemolisina, adicionaram-se em uma placa de microtitulação com fundo em V, $25 \mu \mathrm{l}$ de soro

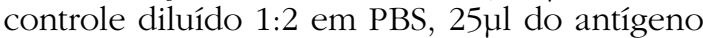

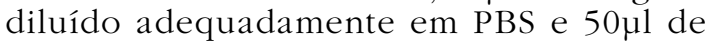
complemento-hemolisina. A placa foi agitada suavemente e incubada a $37^{\circ} \mathrm{C}$ por 45 minutos. Terminada esta primeira incubação, adicionaramse $10 \mu 1$ de eritrócitos tipo $O$ na concetração aproximada de 1.3 x 108 hemácias/ml de PBS, agitou-se suavemente e se incubou a $37^{\circ} \mathrm{C}$ por mais 60 minutos. Procedeu-se a leitura visual, escolhendo-se para seguir a titulação, o frasco de suspensão de complemento-hemolisina que possibilitou discriminar os soros controles positivos e negativos.

$\mathrm{Na}$ segunda etapa, repetiu-se a metodologia anterior, variando as diluições dos soros controles e empregando diferentes volumes da suspensão de complemento-hemolisina do frasco escolhido na primeira etapa, com o intuito de obter reações em amostras diluídas.

Em resumo, na primeira etapa da titulação descobre-se o volume de PBS no qual o complemento-hemolisina deve ser regenerado e na segunda etapa, o volume desta suspensão que deve ser usada na reação.

O título do complemento-hemolisina, determinado por este método, permanece inalterado por três meses, desde que a liofilização seja bem feita e que os frascos de liofilizado sejam armazenados a $4^{\circ} \mathrm{C}$.

Titulação dos antígenos. Para titular os antígenos, foram utilizados dois soros controles negativos e dois soros controle positivos com título determinanado por IFI de 1:80 e 1:640.

Metodologia da prova NFC. Foi realizada de acordo com o protocolo originalmente descrito por Garcia e cols7, com algumas modificações: Os soros foram previamente inativados a $56^{\circ} \mathrm{C}$ por 30 minutos e diluídos em PBS, diretamente na placa de microtitulação com fundo em $\mathrm{V}$, de 1:2 a 1:16, máximo título observado, mantendo um volume final de $25 \mu \mathrm{l}$. Adicionaram-se $25 \mu \mathrm{l}$ de antígeno diluído adequadamente em PBS e o volume de complemento-hemolisina determinado na titulação do lote destes reagentes. Agitou-se suavemente e se incubou a $37^{\circ} \mathrm{C}$ por 45 minutos. Terminada esta primeira incubação, adicionaram-se $10 \mu l$ de eritrócitos tipo $\mathrm{O}$ a concentração de $1.3 \times 108$ hemácias $/ \mathrm{ml}$, agitou-se suavemente e se incubou a $37^{\circ} \mathrm{C}$ por mais 60 minutos. Procedeu-se a leitura visual, considerando-se indicativo de reação positiva a ausência de hemólise e classificando a intensidade de reação como 1+ a 4+, de acordo com o diâmetro do botão de eritrócitos formado.

Imunofluorescência indireta. A IFI foi relizada conforme descrito por Camargo, em 1996, utilizando formas epimastigotas do $T$. cruzi formalizadas e fixadas em lâmina .

Índices de correlação. A correlação entre os resultados obtidos pela NFC e por IFI foram avaliados através dos índices de co-positividade (ICP), co-negatividade (ICN) e concordância (IC) segundo Guimarães e cols 8 , para avaliar a sensibilidade e a especificidade relativa entre os métodos.

\section{RESULTADOS}

Determinaçâo do limiar de reatividade $e$ dos títulos sorológicos para a NFC. A Tabela 1 apresenta os índices de correlação entre a NFC e a IFI obtidos em cada diluição das amostras testadas com cada preparação antigênica, mostrando que o máximo título sorológico encontrado foi 1:16 independente do antígeno utilizado. Considerando o valor mais elevado do IC, o limiar de reatividade determinado para o antígeno EEA foi a diluição 1:4 das amostras onde o IC alcançou o valor 0.87272 . Já para os demais antígenos, o limiar de reatividade foi a diluição $1: 2$, onde o IC apresentou valores de 0.77168 para o antígeno EAE, 0.91017 para o antígeno EEE e 0.84651 para o antígeno EET.

Avaliação da correlação de títulos entre a NRFC e a IFI. Não foi observada nenhuma correlação entre os títulos obtidos pelas duas metodologias de diagnóstico .

Avaliação da sensibilidade da NFC. Buscando confirmar a sensibilidade da NFC indicada pelo ICP, avaliaram-se os resultados obtidos entre um número máximo de 20 amostras de plasmas de pacientes com xenodiagnóstico e/ou hemocultura positivos. Os resultados obtidos foram computados em termos de freqüência de amostras com reação positiva pela NFC. Estes resultados, expressos na Tabela 2, demonstram sensibilidade alta para os antígenos EEE e EET, baixa para o antígeno EEA e mínima para o antígeno EAE. 
Matos A, Ramírez LE. Avaliação de uma nova microtécnica de fixação de complemento (Garcia E Sotelo, 1991) para o diagnóstico da doença de Chagas crônica com diferentes preparações antigênicas. Revista da Sociedade Brasileira de Medicina Tropical 30:493-499, nov-dez, 1997.

Tabela 1 - Índices de correlação entre a nova fixação de complemento e a imunofluorescência indireta obtidos com os diferentes antígenos testados.

\begin{tabular}{|c|c|c|c|c|}
\hline Antígenos & Diluição da amostra & ICP & ICN & IC \\
\hline \multirow[t]{4}{*}{$\overline{\mathrm{EAE}}$} & $1: 2$ & 0,68807 & 0,84454 & 0,77168 \\
\hline & $1: 4$ & 0,58715 & 0,88181 & 0,73515 \\
\hline & $1: 8$ & 0,44954 & 0,91818 & 0,68493 \\
\hline & $1: 16$ & 0,39449 & 0,91818 & 0,65753 \\
\hline \multirow[t]{4}{*}{ EEE } & $1: 2$ & 0,92207 & 0,90000 & 0,91017 \\
\hline & $1: 4$ & 0,79220 & 0,96666 & 0,88622 \\
\hline & $1: 8$ & 0,50649 & 0,97777 & 0,77245 \\
\hline & $1: 16$ & 0,22077 & 0,98888 & 0,64071 \\
\hline \multirow[t]{4}{*}{ EET } & $1: 2$ & 0,81118 & 0,87719 & 0,84651 \\
\hline & $1: 4$ & 0,76237 & 0,92105 & 0,84651 \\
\hline & $1: 8$ & 0,64256 & 0,94736 & 0,80465 \\
\hline & $1: 16$ & 0,54455 & 0,98245 & 0,77674 \\
\hline \multirow[t]{4}{*}{ EEA } & $1: 2$ & 0,89333 & 0,53333 & 0,69696 \\
\hline & $1: 4$ & 0,84000 & 0,90000 & 0,87272 \\
\hline & $1: 8$ & 0,72000 & 0,95555 & 0,84848 \\
\hline & $1: 16$ & 0,45333 & 0,98888 & 0,74545 \\
\hline
\end{tabular}

$\mathrm{ICP}=$ índice de co-positividade; $\mathrm{ICN}=$ índice de co-negatividade; $\mathrm{IC}=$ índice de concordância; $\mathrm{EAE}=$ extrato aquoso de epimastigotas $\mathrm{EEE}=$ extrato etanólico de epimastigotas; $\mathrm{EET}=$ extrato etanólico de tripomastigotas; EEA= extrato etanólico de amastigotas .

Tabela 2 - Freqüência de resultados positivos para nova fixação de complemento com os diferentes antígenos estados entre amostras de plasma provenientes de pacientes com diagnóstico parasitológico de doença de Chagas.

Antígeno Diluição do plasma Freqüência de testes positivos EEE $1: 2 \quad 1$ EET $1: 2 \quad 1$

$\begin{array}{lll}\text { EEA } & 1: 4 & 2 / 3\end{array}$

EAE $\quad 1: 2$

EAE $=$ extrato aquoso de epimastigotas; $\mathrm{EEE}=$ extrato etanólico de epimastigotas; EET = extrato etanólico de tripomastigotas EEA = extrato etanólico de amastigotas.

Nesta Tabela foram considerados apenas os resultados obtidos no limiar de reatividade escolhido para cada antígeno.

Avaliação da especificidade da NFC. A Tabela 3 apresenta a freqüência de resultados falso-positivos devido à reação cruzada com outras patologias ou ao consumo do complemento pelo complexo imune do fator reumatóide. As amostras de soro provenientes de pacientes com diagnóstico de leishmaniose tegumentar americana (LTA) apresentaram elevada freqüência de reações cruzadas com todos os antígenos, porém a frequência foi maior quando se utilizou antígenos preparados a partir da forma epimastigota do T. cruzi (EAE e EEE). Entre as amostras de soro de portadores de toxoplasmose, a freqüência de reação cruzada foi alta ao se utilizar os antígenos preparados a partir de tripomastigotas (EET) ou amastigotas (EEA) e baixa ao se empregar os antígenos EAE ou EEE. Reações cruzadas com Lues não foram observadas com os antígenos EAE ou EEA. Reações falso-positivas devido à presença do fator reumatóide não foram encontradas quando o antígeno EEA foi utilizado.

Tabela 3 - Freqüência de resultados falso-positivos para nova fixação de complemento obtidos entre amostras de soro provenientes de portadores de outras patologias

\begin{tabular}{|c|c|c|c|c|c|c|}
\hline Antígeno & Diluição da Amostra & Malária & Leishmaniose & Lues & Toxoplasmose & Doença reumática \\
\hline$\overline{\mathrm{EAE}}$ & $1: 2$ & 0 & $3 / 5$ & 0 & $1 / 5$ & 1 \\
\hline EEE & $1: 2$ & 0 & $3 / 4$ & $1 / 2$ & $1 / 4$ & $1 / 2$ \\
\hline EET & $1: 2$ & 0 & $1 / 2$ & $1 / 4$ & $3 / 4$ & $1 / 2$ \\
\hline EEA & $1: 4$ & 0 & $1 / 2$ & 0 & $1 / 2$ & 0 \\
\hline
\end{tabular}

$\overline{\mathrm{EAE}}=$ extrato aquoso de epimastigotas; $\mathrm{EEE}=$ extrato etanólico de epimastigotas; $\mathrm{EET}=$ extrato etanólico de tripomastigotas; EEA= extrato etanólico de amastigotas.

Nesta Tabela foram considerados apenas os resultados obtidos no limiar de reatividade escolhido para cada antígeno.

\section{DISCUSSÃO}

Almeida e Fife1 relataram que os títulos sorológicos, obtidos através da reação clássica de fixação de complemento, variam de 1:1 a $1: 18$, para a maioria dos pacientes chagásicos crônicos. Salvo as diferenças metodológicas, este dado concorda com os resultados encontrados em nossos experimentos, onde os títulos determinados para os soros pela NFC variaram 
Matos A, Ramírez LE. Avaliação de uma nova microtécnica de fixação de complemento (Garcia E Sotelo, 1991) para o diagnóstico da doença de Chagas crônica com diferentes preparaçôes antigênicas. Revista da Sociedade Brasileira de Medicina Tropical 30:493-499, nov-dez, 1997.

de $1: 2$ a 1:16, indicando que o complemento e a hemolisina, obtidos conjuntamente em cobaias, e o revelador constituído de eritrócitos humanos tipo O, além de estáveis e de fácil obtenção e titulação, mostraram-se adequados. Não observamos correlação entre os títulos sorológicos previamente determinads pela IFI e os títulos obtidos pela NFC para nenhum dos antígenos testados. Isto sugere pequena participação dos antígenos de superfície encontrados nas formas epimastigotas do $T$. cruzi na composição das diferentes preparações antigênicas testadas, independente da forma evolutiva empregada ou do solvente utilizado na extração.

Dentre todas as preparações antigênicas testadas, o antígeno que se mostrou mais sensivel foi o EEE, cujo valor de ICP alcançou 0,92207, similar ao encontrado por Garcia e cols 7 , reconhecendo todas as amostras de plasmas de pacientes com diagnóstico parasitológico de doença de Chagas. Já o antígeno EAE, demostrou-se ser o menos sensível, tendo apresentado baixa frequência de acerto entre amostras de plasma de pacientes determinados parasitologicamente como chagásicos. Estes resultados diferem daqueles apresentados por Almeida e Fife 1 , que apontam o extrato aquoso de epimastigotas como um antígeno de alta sensibilidade. Tal discrepância deve-se, possivelmente, ao fato de que o protocolo para produção deste antígeno não foi descrito em detalhes pelos autores, dificultando sua fiel reprodução. Já o comportamento dos antígenos EET e EEA quanto a sensibilidade foi similar entre si e intermediário ao apresentado pelas preparações EEE e EAE.

A especificidade da NFC com os diferentes antígenos empregados foi avaliada através do ICN e da frequência de resultados falso-positivos entre amostras de soro de portadores de outras patologias, revelando que o antígeno EEE, na verdade é menos específico do que foi descrito por Garcia e cols7 ao relatarem concordância de $99 \%$ com o teste de ELISA. Esta diferença de resultados deve-se ao fato de termos utilizado amostras de soro provenientes de portadores de diversas patologias para avaliar possíveis reações cruzadas, enquanto que os autores anteriores restringiram-se a utilizar amostras de soro de portadores de esquistossomose mansoni, a qual não é descrita como causa de reações falso-positivas no diagnóstico sorológico da doença de Chagas. Analisando a frequência de reações falso-positivas entre amostras de portadores de outras patologias, não foi observada nenhuma reação cruzada com soro de portadores de malária, fosse ela causada pelo Plasmodium vivax ou pelo Plamodium faciparum. As reações cruzadas com Leishmania sp foram mais freqüentes quando se utilizaram antígenos preparados a partir de epimastigotas (EAE e EEE) enquanto que a freqüência de reações cruzadas com Toxoplasma gondii foi mais elevada quando foram utilizados antígenos preparados a partir das formas tripomastigotas (EET) ou amastigotas (EEA), demonstrando uma nítida diferenciação entre a composição das preparações antigênicas de epimastigotas e de formas obtidas de cultura celular. Também, as reações cruzadas com lues ocorreram com freqüência muito menor quando o antígeno EAE foi utilizado, indicando que o benzeno é mais eficiente do que a acetona para extrair lipídeos. Já a ausência de reações falso-positivas devido à presença do fator reumatóide, quando o antígeno EEA foi empregado, deve-se, provavelmente ao limiar de reatividade mais alto e a dificuldades enfrentadas na conservação das amostras.

Comparando os resultados obtidos para as mesmas amostras de soro com os diferentes antígenos empregados, não foi encontrada coincidência total entre as reações falsonegativas ou falso-positivas (dados não apresentados). A mesma amostra de soro que caracterizou uma reação falso-negativa com um antígeno foi reconhecida como positiva por outro. O mesmo aconteceu quando foi analisada a coincidência de reações falsopositivas entre amostras de soro provenientes de doadores de sangue, testadas com os diferentes antígenos empregados. Isto sugere que foram extraídos determinantes antigênicos distintos a partir das diferentes formas evolutivas do T. cruzi e que a água e o etanol apresentam propriedades diferenciadas como extrator de moléculas antigênicas das formas epimastigotas.

Especificamente sobre o antígeno EEA, não foi encontrada, em levantamento bibliográfico, nenhuma referência à utilização de amastigotas isoladas no preparo de antígenos destinado à determinação de anticorporpos fixadores de complemento. No entanto, sua avaliação como antígeno para outras metodologias de diagnóstico é consistente. Primavera e cols11 
Matos A, Ramírez LE. Avaliação de uma nova microtécnica de fixação de complemento (Garcia E Sotelo, 1991) para o diagnóstico da doença de Chagas crônica com diferentes preparaçôes antigênicas. Revista da Sociedade Brasileira de Medicina Tropical 30:493-499, nov-dez, 1997.

indicaram sua utilização para a pesquisa de IgA através da IFI. Araújo e Guptill2 apresentaram resultados que recomendam a utilização de preparações antigênicas de amastigotas de $T$. cruzi para IFI e ELISA e ainda, Matsumoto e cols9 relataram que as médias geométricas dos títulos sorológicos obtidos por IFI são duas a quatro vezes maiores para amastigotas em relação a epimastigotas. No presente trabalho, não foi observada diferença significativa no comportamento da NFC utilizando o extrato etanólico de amastigotas EEA em relação aos demais antígenos testados, uma vez que o valor do ICN foi igual ao apresentado pelo antígeno EEE e que tanto o ICP quanto a ocorrência de reações cruzadas foram similares aos achados relativos ao antígeno EET. No entanto, os resultados obtidos com o antígeno EEA sugerem ser possível melhorar sua performance eliminando os resíduos da monocamada celular de cultivo durante a preparação do antígeno, como demonstrado por Neva e Gam ${ }^{10}$, e extraindo os lipídeos com benzeno em substituição a acetona.

Portanto, entre as quatro preparações antigênicas testadas (EAE, EEE, EET e EEA), o antígeno EEE, o qual foi preparado segundo a metodologia descrita por Garcia e cols 7 , mostrou-se ser o mais adequado para fins de diagnóstico, apresentando-se estável, sensível, com boa especificidade e excelente reprodutibilidade. Os resultados de nossos experimentos apontam a NFC como uma microtécnica semi-quantitativa rápida, sensível, barata e de fácil execussão, aplicável ao diagnóstico da doença de Chagas crônica e que, por sua simplicidade, merece estudos complementares para padronização da técnica e posterior adaptação aos laboratórios de diagnóstico.

\section{SUMMARY}

From this present data it has been evaluated a new complement fixation test, comparatively to indirect immunofluorescence to diagnose chronic Chagas' disease, utilizing one watery extract of epimastigotes of Trypanosoma cruzi and three other ethanolic extracts: one from epimastigotes, one from tripomastigotes and a third one of amastigotes obtained from cultures. Utilizing 236 serum samples indirect immunofluorescence test was performed: 109 positives (20 of them with positive parasitologic diagnostic) and 127 negatives (96 of healthy blood donors and 31 with other diseases). The results have showed that is possible a positive reaction in diluted samples up to 1:16. The best limits of reactivity found were the dilutions 1:4 for the ethanolic extract of amastigotes and 1:2 for the others antigens. The correlation index among the new complement fixation test and indirect immunofluorescence test showed that the ethanolic extract from epimastigotes was the best antigen to be utilized to diagnosis purposes. Its co-positivity index with indirect immunofluorescence was 0,92207 and the conegative index was 0,90000. Concluding, the new complement fixation test showed itself as a fast, sensible, easily applicable semiquantitative microthecnique to the diagnosis of chronic Chagas' disease.

Key-words: Chagas' disease. Diagnosis. Complement fixation.

\section{REFERÊNCIAS BILIOGRÁFICAS}

1. Almeida JO, Fife EH. Método de fijación del complemento estandarizado cuantitativamente para la evaluacion critica de antigenos preparados com Trypanosoma cruzi. Publicación científica $\mathrm{n}^{\circ}$ 319, Organizacion Panamerican de la Salud, Oficina Sanitaria Panamericana, Oficina Regional de la Organización Mundial de la Salud, Washington, DC, USA, 1976.

2. Araújo FG, Guptill D. Use of antigen preparations of amastgote stage of Trypanosoma cruzi in serology of Chagas'disease.The American Journal of Tropical Medicine and Hygiene 33:362-371, 1984.

3. Camargo EP.Growth and diferentiation in Trypanosoma cruzi I. Origin of metacyclic trypanosomes in liquid media. Revista do Instituto de Medicina Tropical de São Paulo 6:93100, 1964.

4. Camargo ME. Fluorescent antibody test for diagnosis of american tripanosomiasis. Technical modification employing preservated culture forms of T. cruzi in slide test. Revista do Instituto de Medicina Tropical de São Paulo 8:227-234, 1966.

5. Dias JCP. Chagas' disease control: current status and perspectives. Memórias do Instituto Oswaldo Cruz 88 (supl):93-96, 1993.

6. Garcia E, Sotelo J.A new complement fixation for diagnosis of neurocisticercosis in cerebrospinal fluid. Journal of Neurology 238:379-382, 1991.

7. Garcia E, Ramirez LE, Monteon V, Sotelo J. Diagnosis of american trypanosomiasis (Chagas' 
Matos A, Ramírez LE. Avaliação de uma nova microtécnica de fixação de complemento (Garcia E Sotelo, 1991) para o diagnóstico da doença de Chagas crônica com diferentes preparações antigênicas. Revista da Sociedade Brasileira de Medicina Tropical 30:493-499, nov-dez, 1997.

disease) by new complement fixation test. Journal Clinical Microbiology 33:1034-1035, 1995.

8. Guimarães MCS, Coutinho SG, Antunes CMF. Normas para a sorologia de moléstias parasitárias. Noticiário. Revista da Sociedade Brasileira de Medicina Tropical 20:55-58, 1987.

9. Matsumoto TK, Shimizu SH, Nakamura PM, Andrade Jr. HF, Umezawa E. High resolution of Trypanosoma cruzi amastigote antigen in serodiagnosis os different clinical forms of Chagas' disease. Journal Clinical of Microbiology 31:1486-1492, 1993.
10. Neva FA, Gam AA. A complement-fixing antigen from Trypanosoma cruzi grown in cell cultures. The American Journal of Tropical Medicine and Hygiene 26:37-46, 1977.

11. Primavera K, Umezawa ES, Peres BA, Camargo ME, Shimizu SH. Chagas' disease: IgA, IgM and IgG to $T$. cruzi, amastigotes, trypomastigotes and epimastigotes antigens in acute and in different forms of the disease. Revista do Instituto de Medicina Tropical de São Paulo 32:172-180, 1990. 